\title{
O Poeta Entre o Literário, o Político e a Polèmica: a Recepção de Dante, no Romantismo Francês
}

\author{
Celina Maria Moreira de Mello*
}

RESUMO: Este ensaio desenha um panorama da recepção, na França, da obra do poeta Dante Alighieri por eruditos, tradutores, pintores e poetas, em sua atuação de mediadores culturais, em uma perspectiva sócio-histórica e discursiva. São apontados como exemplo dois modos diversos de apropriação da obra do poeta florentino: Dante visto como um perigoso templário socialista e uma polêmica, na imprensa, provocada pela biografia de Dante, de autoria de Charles-Claude Fauriel, publicada na Revue des Deux Mondes em $1^{\circ}$ de outubro de 1834. Para além dos posicionamentos conflitantes em uma perspectiva da constituição da autonomia do campo literário, podemos ver o choque de grupos e veículos de publicação rivais, assim como ler um capítulo das narrativas de construção de identidades nacionais.

PALAVRAS-CHAVE: Dante; romantismo francês; transposição de arte; polêmica.

ABSTRACT: Questo saggio disegna un panorama della ricezione, in Francia, dell'opera del poeta Dante Alighieri dagli eruditi, traduttori, pittori e poeti, nel loro ruolo di mediatori culturali in una prospettiva socio-storica e discorsiva. Vengono evidenziati como esempio due modi diversi di apropriazione dell'opera del poeta fiorentino: Dante visto come un pericoloso templario socialista e una polemica, sulla stampa, provocata dalla biografia di Dante di Charles-Claude Fauriel, pubblicata sulla Revue des Deux Mondes il $1^{\circ}$ ottobre 1834. Al di là delle posizioni conflittanti in una prospettiva della costituzione dell'autonomia del campo letterario, possiamo vedere lo scontro tra gruppi e veicoli di pubblicazione rivali, così come leggere un capitolo delle narrative di costruzione delle identità nazionali.

* Universidade do Rio de Janeiro, Rio de Janeiro, RJ (Brasil) - celina.mello@pq.cnpq.br 
PAROLE CHIAVE: Dante; romanticismo francese; trasposizione d'arte; polemical.

ABSTRACT: This essay draws a panorama of reception, in France, of the work of the poet Dante Alighieri, by scholars, translators, painters, and poets, in their role of cultural mediators, in a socio-historical and discursive perspective. Two different appropriations of the work of the Florentine poet are demonstrated as an example: Dante seen as a dangerous socialist Templar and a controversy, in the press, provoked by Dante's biography, by Charles-Claude Fauriel (1772-1844), published in the Revue es Deux Mandes on October Mst, 1834. In addition to the conflicting positions in a perspective that aimed to constitute the literary field autonomy, we can see the confrontation of rival groups and publishing vehicles, the same happens with the reading of a chapter of narratives focused on the construction of national identities. KEYWORDS: Dante; French romanticism; transposition of art; controversy. 
os primeiros anos da Monarquia de Julho (1830-1836), regime constitucional que se instaurou na França após três dias de insurreição provocada, entre outros acontecimentos, por uma revolta contra um endurecimento das leis de censura aos impressos, há uma expansão de periódicos, jornais de opinião e revistas voltadas para um leque bastante diverso de temas, entre as quais se destacam as revistas literárias. Ao longo da Monarquia de Julho, o boom tecnológico, o aumento do número de leitores e o barateamento dos custos de impressão, acarretam um aumento de tiragens e ampliação das redes de distribuição, as quais acompanham de início as novas linhas de trens e, mais tarde, as rotas de circulação de navios transatlânticos.

As revistas que participam do movimento romântico apresentam um forte interesse pelas literaturas estrangeiras modernas, sobretudo alemã e inglesa. A tradução assume uma enorme 
importância, sendo pensada para alcançar um novo público leitor, pertencente a uma burguesia ascendente, não cosmopolita, não viajante e não poliglota. É dado destaque a textos que fundam a expressão literária e cultural em outras línguas vernáculas, ou que se vinculam a registros escritos de tradições orais. Para reprodução pela imprensa, são escolhidos preferencialmente contos e poemas, pois suas dimensões permitem que sejam publicados em sua íntegra. No que se refere à presença da literatura e da arte italiana, a grande ênfase, nos folhetins críticos ou em ensaios na imprensa francesa, é dada, sobretudo, ao teatro e à ópera.

Há, igualmente, numerosas traduções de obras literárias italianas, em um fenômeno a que Giovanni Dottoli (2004, p. 60) chama uma "explosão de traduções"1. Desse modo, Dante, Tasso, Ariosto, Boccaccio, Machiavel e Petrarca conquistam a França (DOTTOLI, 2004, p. 60), e há um grande interesse por autores mais recentes, como Vittorio Alfieri, Ugo Foscolo e Vincenzo Monti. Devem ser mencionados o sucesso de Alessandro Manzoni e, alguns anos mais tarde, a acolhida feita à obra de Giacomo Leopardi por Sainte-Beuve que o define como "o clássico por excelência entre os românticos" (VEGLIANTE, 1999, p. 72).

O mais traduzido escritor italiano contemporâneo dos românticos franceses é Silvio Pellico, autor de Le miei prigioni (em francês, Mes prisons), "verdadeiro best-seller italiano na França" (VEGLIANTE, 1999, p. 73). Também deve ser lembrada a tradução de La scienzia nuova, de Giambattista Vico, por Jules Michelet, em 1827. Destaca-se, ainda, a figura de Giuseppe Mazzini, que teria se inspirado em Jeunes France para fundar a Giovane Italia, e cujo livro República e realeza na Itália (1850) foi publicado, na França, com tradução e prefácio de George Sand.

As várias traduções da Divina comédia de Dante apresentam inúmeras opções e soluções diversas, que oscilam entre tentativas de traduções fiéis, transliterações em prosa ou adaptações em verso nem sempre felizes (VEGLIANTE, 1999, p. 78). Para Giovanni Dottoli (2004, p. 27), uma questão que se coloca em relação à tradução nesse período e que diz respeito à cor local ${ }^{2}$ é a relação entre a língua de partida e a língua de chegada. Nessa perspectiva, "Dante Alighieri deveria ser traduzido para o francês da Idade Média". Para a tradução do Inferno de Dante, Emile Littré, em 1879, foi ainda mais conservador: "seu modelo é o francês do século XIII. Littré procede por correspondência de idiomas, para tentar restituir uma atmosfera original." (DOTTOLI, 2004, p. 46).

A primeira grande obra de referência sobre a recepção de Dante, na França, foi a obra do filólogo romanista belga Albert Counson publicada em 1906, Dante en France (FAIDER, 1933). Logo em sua introdução, Counson (1906, p. 1) afirma: "ele [Dante] permanecia o ancestral

1 Esta e as demais citações foram traduzidas pela autora deste artigo.

2 A cor local não deve ser entendida apenas em sua dimensão geográfico-cultural, mas a respeito de uma visão do texto literário projetado na história. Introduz-se a dimensão da distância no tempo, que rompe com o projeto estético e político de uma atemporalidade humanista em função da qual eram traduzidos e lidos os textos da Antiguidade. 
inimitável cuja grandeza deveria melhor aparecer com o recuo dos séculos". Mais adiante, ele enfatiza que os pintores, com mais êxito do que os poetas, reverenciaram Dante.

O quadro de estreia de Eugène Delacroix, no Salão de 1822, Dante et Virgile aux enfers [Dante e Virgílio nos infernos], causa um grande impacto, sendo considerado o manifesto romântico da pintura. O quadro, que ficará conhecido como La barque de Dante (A barca de Dante), suscita vívidas polêmicas (COUNSON, 1906). A nota do catálogo explica: "Dante e Virgílio, conduzidos por Flégias, atravessando o lago que cerca as muralhas da cidade infernal de Dite. Culpados se prendem à barca e tentam subir; entre eles Dante reconhece os florentinos" (JULLIAN, 1963, p. 37-38). O quadro, embora em respeito à tradição da écfrasis, trazia a novidade de buscar inspiração em Dante e chocou os críticos por sua violência e agressividade, no tema e nas cores.

No que se refere à forma, há um intertexto evidente em relação a outras obras picturais e, para Jullian (1963, p. 40), biógrafo do pintor, "encontramos na torsão dos corpos o Michelangelo da Sistina". Seu valor expressivo é único: “Todos os rapazes da idade de Delacroix ${ }^{3}$ reviram nessa barca suas sombrias meditações, suas exaltadas leituras, seu desespero [...] [é uma] 'exaltação do desespero"" (JULLIAN, 1963, p. 41-42).

Não foi esse o único encontro entre Delacroix e a poesia de Dante, de que o pintor era um entusiasmado leitor: em vários momentos de seu diário, Delacroix expressa sua admiração pelo poeta. Em 7 de maio de 1824, ele registrou que Dante lhe servia não apenas de modelo, mas de inspiração para seu processo criativo:

Dante é realmente o primeiro entre os poetas. Com ele nos arrepiamos como diante da coisa. Nisso ele é superior a Michelangelo, ou, melhor dizendo, diferente; pois ele é sublime de uma outra maneira [...] e é com isso precisamente que sempre sonhei, sem o definir. Seja você na pintura precisamente isso. É uma carreira única. (DELACROIX, 1996, p. 77).

Assim, há outras obras suas inspiradas pelo poeta. Destaca-se $A$ justiça de Trajano, quadro exposto pela primeira vez no Salão de 1840, inspirado pelo canto X, do Purgatório de Dante. No libreto da exposição do Museu de Rouen, a menção à tela vem acompanhada por uma longa passagem do Purgatório, "extraída da tradução realizada por seu amigo Anthony Deschamps". Théophile Gautier, à época o mais destacado crítico de arte, em seu Salão de 1840, publicado no jornal La Presse, considera que é o mais importante quadro da exposição:

$3 \mathrm{O}$ pintor tinha à época 22 anos. 
A Justiça de Trajano é, certamente, o mais importante quadro do Salão; ele atrai imperiosamente a atenção pela energia da cor, a aspereza selvagem da pincelada, a estranheza da composição, e pela turbulência e inquietação febril que caracterizam todos os quadros do sr. Eugène Delacroix, nos quais, por mais bem acabados que sejam, afloram sempre um desejo e a vontade de um resultado superior. (GAUTIER, 1840).

Gautier (1840) registra a inspiração literária da obra e transcreve na íntegra, para os leitores do jornal, o poema de Dante que inspirara Delacroix:

O senhor Delacroix, que lê os poetas com amor e inteligência, tirou seu tema da Divina comédia. - "É a Justiça de Trajano". - Como esse fato é pouco conhecido, transcrevemos aqui os belos versos de Antony Deschamps, que traduziu Dante com um sentimento e uma fidelidade muito rara entre os tradutores franceses. (GAUTIER, 1840).

E há também os afrescos na cúpula da biblioteca do Senado, no palácio do Luxembourg, Dante et Virgile dans les limbes [Dante e Virgílio no limbo], pintados por Delacroix entre 1841 e 1846, que são inspirados pelo Canto IV do Inferno. O pintor, em uma nota publicada pela revista L'Artiste, em 1846, descreve o tema:

A pintura da cúpula, no centro da biblioteca, representa o limbo descrito por Dante no Canto IV de seu Inferno. É uma espécie de Elyseu, em que estão reunidos os grandes homens que não receberam a graça do batismo: "Sua grande fama, que ainda vive lá no alto em vossa terra, lhes valeu tão preciosa distinção". Estas palavras, tiradas do poema, estão escritas em um cartucho que é segurado por duas crianças aladas e indicam o tema. [...] A composição está disposta em quatro partes ou grupos principais. O primeiro, que é o mais importante e, de certo modo, o centro e o destaque do quadro, [...], representa Homero apoiado em um cetro, acompanhado pelos poetas Ovídio, Lucano e Horácio. Ele acolhe Dante, que lhe é trazido por Virgílio. (DELACROIX, 1847, p. 151). 
Há, nesses afrescos, uma curiosidade assinalada por Sérullaz: Dante é pintado com os traços de Chopin, amigo de Delacroix, manifestação inconteste da fraternidade das artes que une os românticos.

Delacroix se inspirou livremente dos afrescos pintados por Rafael, na Câmara da Assinatura (Stanza della Segnatura) no Vaticano. Como o pintor italiano já havia feito, Delacroix não hesitou em introduzir, em seus grupos, modelos que provinham do mundo contemporâneo. (Chopin empresta sua fisionomia a Dante, Virgílio seria o próprio Delacroix e Aspásia seria George Sand). (SÉRULLAZ, 1963 apud LOICQ-BERGER, 2005).

Devem ser mencionados outros pintores ${ }^{4}$, igualmente inspirados por Dante, com quadros não menos famosos, como Francesca da Rimini and Paolo Malatesta appraised by Dante and Virgil, mais conhecido como Paolo e Francesca, do qual Ary Scheffer pintou várias versões - a primeira se encontra em Londres, na Wallace Collection. Exposto pela primeira vez no Salão de 1835 , foi um dos quadros mais célebres de seu tempo e um dos mais caros do século XIX, adquirido pelo marquês de Hetford em 1870 (WALLACE..., 1997, p. 83). Desde então, essa obra integra o acervo do museu, que explica em seu catálogo:

O tema, tirado do Inferno de Dante, mostra o poeta conduzido por Virgílio, observando Paola e Francesca, no segundo círculo do inferno, ao qual foram condenados pelo adultério. Os amantes foram apunhalados pelo marido de Francesca, irmão mais velho de Paolo. A moldura muito trabalhada, na qual podemos ler frases do texto de Dante, foi concebida para um de seus proprietários, o colecionador russo Anatole Demidoff. (WALLACE..., 1997, p. 83).

Ainda de Ary Scheffer, igualmente inspirado por Dante, há o quadro A visão: Dante e Beatriz (1846), que se encontra no Museu Wolverhampton Art Gallery, no Reino Unido 5 .

Dante inspirou do mesmo modo romancistas, dramaturgos e poetas. Merecem destaque: o título da Comédia humana de Honoré de Balzac; a estrutura tripartite do poema Eloá (1824), de autoria de Alfred de Vigny, igualmente amigo de Anthony Deschamps, tradutor de Dante já mencionado; Chateaubriand, que evoca o poeta florentino em seu passeio ao Vesúvio

4 Também devemos lembrar a edição do Inferno (1857), com ilustrações de Gustave Doré, que se igualam em beleza às mais notáveis telas.

5 Uma segunda versão, de 1851, se encontra exposta no Museu de Belas Artes, em Boston. 
(COUNSON, 1906, p. 11); Madame de Staël, em seu romance Corinne (1807); e os poetas Lamartine, Baudelaire e Verlaine (VEGLIANTE, 1999, p. 79).

Dante está igualmente presente no Prefácio de Cromwell (1827), de Victor Hugo (1972), considerado o manifesto do drama romântico. O poeta francês, para legitimar a proposta de renovação do teatro sublime, chega a apresentar a Divina comédia como sendo um drama e não uma epopeia:

o drama é a poesia completa - Na poesia moderna, tudo leva ao drama. O Paraíso perdido é um drama, antes de ser uma epopeia [...] Quando Dante terminou seu terrível Inferno [...] o instinto de seu gênio lhe fez perceber que esse poema multiforme é uma emanação do drama, não da epopeia; e no frontispício do gigantesco monumento, com sua pluma de bronze ele escreveu: Divina comédia. (HUGO, 1972, p. 56-59).

Pintores, tradutores, poetas e críticos operam como mediadores culturais, vetores de transferências culturais, entre a cultura italiana do medievo e a cultura francesa do romantismo, que, de acordo com Michel Espagne, ressignificam a obra de Dante, em um processo de mestiçagem ou hibridismo (ESPAGNE, 2013). A emancipação do modelo evidencia que seus diversos modos de tradução e de leitura interpretativa dizem tanto sobre Dante quanto sobre seus intérpretes - a obra de Dante opera como uma tela em branco, em que cada um projetaria suas posições estéticas, religiosas e até mesmo políticas. A obra do poeta assume, dessa maneira, um lugar de texto fundador do romantismo francês e seus diversos modos de apropriação expressam a luta de diferentes grupos de agentes no campo literário para estabelecer sua hegemonia no processo de apropriação e interpretação (BOURDIEU, 1992).

Um caso de leitura extrema é o de um Dante socialista, como ele é apresentado pelo deputado Eugène Aroux (1854) em Dante hérétique, révolutionnaire et socialiste, révélations d'un catholique sur le Moyen Age [Dante, herético, revolucionário e socialista, revelações de um católico sobre a Idade Média], livro dedicado ao Papa Pio IX para adverti-lo de que Dante Alighieri "estava por sua fé e suas doutrinas fora da comunhão católica" e denunciar sua "hostilidade e o artifício por meio do qual conseguiu por tanto tempo dissimular sua hostilidade". Para Aroux, Dante era tanto mais perigoso por ser um poeta genial. O deputado francês lamentou ter realizado em 1842 uma tradução literal da Divina comédia, diagnosticando sua época como 
de "decadência literária", um tempo em que "o gênio foi abafado pelo materialismo" e afirmando que cabe à crítica que seja independente da política servir "à religião e à humanidade". Debaixo das "dobras da capa poética [de Dante] que esconde todo um arsenal de heresias" ele percebe seu "ódio do catolicismo e a vontade de derrubar o edifício social" (AROUX, 1854, p. IX-XI) cujo princípio conservador era o dogma da revelação. Aroux deplorou sua tradução, que ele considerava ruim por ser literal - aliás, ele remanejou posteriormente, afirmando que fizera como os outros tradutores: "traduzi o que não entendia" (AROUX, 1854, p. XI).

Trata-se não somente de uma disputa de linhas de interpretações, mas também de uma discussão quanto a métodos de leitura crítica. Aroux, católico, político e estudioso da Idade Média, colocou a questão, ainda atual na área de letras, do conhecimento exigido e das leituras necessárias, para que se possa fazer uma crítica pertinente. Em sua avaliação negativa, seus contemporâneos conheceriam, no máximo, os Sonetos de Petrarca, o Decameron de Boccaccio e a Jerusalém de Tasso: "É preciso mais para escrever no correr da pena um artigo crítico brilhante sobre a literatura italiana?" (AROUX, 1854, p. XII) Ele recusou então uma discussão teológica e o papel de erudito, almejando ser "claro e conciso" (AROUX, 1854, p. XIII), para poder alcançar o mais amplo público, e defende seu posicionamento como resultando do estudo de "um ponto de crítica histórica e literária" e sua interpretação como uma "opinião literária e histórica" (AROUX, 1854, p. XIV-XV).

A leitura que Aroux oferece a um amplo público explora as conexões gnósticas e maniqueístas entre a cruzada contra os albigenses, as heresias de que foram acusados os templários, a poesia clus (fechada) ou car (preciosa) provençal e a obra de Dante. Ele nos leva diretamente ao obscuro universo semi-histórico e semificcional - muito próximo daquele que vemos construído por Umberto Eco em O pêndulo de Foucault - quando afirma "em alma e consciência": "os Templários eram culpados e tiveram como cúmplice Dante Alighieri” (AROUX, 1854, p. 21).

Em sua interpretação, com o objetivo de enganar o Vaticano - cuja atenção fora despertada pelos élans místicos da poesia do gai savoir que afirma que o Amor existe (e seria o amor por uma dama misteriosa, uma Madonna, comparada à estrela do Oriente, e de inspiração gibelina, o que poria em perigo o catolicismo) -, Dante e seus amigos teriam imaginado

combinar dois elementos em antagonismo completo, enxertar o ramo ortodoxo no tronco gibelino, mostrar uma Beatriz erótica que se transforma logo em uma Beatriz filosófica, de essência heterodoxa, com um disfarce teológico. Ou 
seja, substituir o platonismo pelo dogmatismo ou confundi-los a tal ponto que o primeiro servisse de disfarce ao outro, com tudo que este escondia de hostil contra a autoridade apostólica, de subversivo em relação às crenças e à ordem estabelecida. (AROUX, 1854, p. 30).

E para executar esse plano, que Aroux atribui à genialidade do poeta, Dante o anuncia na Vida nova, o executa na Divina comédia, e explica no Convívio e em seu tratado sobre os usos do idioma vulgar. Isso para explicar o porquê de chamá-lo herético. Quanto a socialista e revolucionário, temos que atravessar as 476 páginas deste estudo não erudito, para chegarmos à afirmação de que Dante teria visado a uma "verdadeira revolução social" (AROUX, 1854, p. 420). Aroux conclui dizendo ser Dante "Socialista, tanto quanto se podia ser no século XIV, ele pretendia subverter a sociedade, para reorganizá-la em novas bases, constituir uma monarquia universal, tão impossível de realizar quanto uma república universal" (AROUX, 1854, p. 420). Em nota, ele responde por antecipação àqueles que o acusarão de ter dito que Dante era maçom, ele apenas afirma que Dante havia sido iniciado secretamente à sociedade dos Templários (AROUX, 1854, p. 423, nota 1).

Na história da recepção da obra de Dante, pelos românticos franceses, destaca-se CharlesClaude Fauriel, historiador da cultura, linguista, erudito e crítico, um dos mais respeitados especialistas de literaturas estrangeiras, amigo de Manzoni (ele traduzira Il Conte di Carmagnola em 1823) e de Tommaseo. Michel Espagne, ao discutir a relação entre as transferências culturais estrangeiras e a identidade nacional, analisa o percurso de Claude Fauriel, que teria feito a mediação entre uma geração de revolucionários e uma geração mais jovem, a dos historiadores da Revolução Francesa, fundadores da universidade francesa moderna, tais como François Guizot, Victor Cousin e Augustin Thierry (ESPAGNE, 1991, p. 8)

Fauriel, nomeado por Guizot, após a Revolução de Julho, assumira, em 1830, a cátedra de literaturas estrangeiras na Sorbonne, que fora criada especialmente para recebê-lo. Ele dominava o italiano, o alemão, o inglês e, além do latim e do grego antigo, interessava-se pelo sânscrito, o árabe, o provençal, o castelhano, o português, o siciliano, o romeno, o basco e o bretão. É considerado por seus biógrafos um dos fundadores da literatura comparada, área para a qual ele transpôs seus vastos conhecimentos de filologia e gramática comparada.

Ministrou cursos que foram memoráveis. No ano acadêmico de 1832-1833, ministrou um curso sobre a poesia provençal - para Fauriel viera da Provença a inspiração para a primeira 
geração de poesia italiana, o que foi posteriormente contestado (COUNSON, 1906, p. 153). Em 1833-1834, ministrou um curso sobre a obra de Dante, de que resultará uma biografia do poeta, publicada em 1834 na Revue des Deux Mondes. O conjunto das aulas formou, em 1854, uma publicação póstuma: Dante et les origines de la langue et la littérature italiennes; cours fait à la Faculté de Lettres par M. Fauriel [Dante e as origens da língua e da literatura italiana, curso proferido pelo sr. Fauriel na Faculdade de Letras], que foi logo a seguir, em 1856, traduzida para o italiano por Girolamo Ardizzone.

Em suas aulas, Fauriel não se limitava aos procedimentos dos gramáticos e filólogos, mas empreendeu um estudo detalhado dos acontecimentos contemporâneos, das instituições de Florença e da vida do poeta. Ele tratou, igualmente, da história política do século XIII, as lutas entre a Igreja e o Império, a guerra entre nobres e plebeus, a rivalidade das cidades, e as intervenções dos estrangeiros, assim como acrescenta informações sobre a língua italiana antes de Dante, fundando, assim, a tradição dos estudos sobre o poeta, na universidade francesa.

A biografia de Dante, de autoria de Fauriel, foi publicada em $1^{\circ}$ de outubro de 1834, na Revue des Deux Mondes, provocando uma polêmica que revela a disputa por posições hegemônicas no campo literário. Aqui, uma breve observação de caráter metodológico: a pesquisa sobre a circulação de autores, obras, estéticas e temas deve considerar, no que diz respeito às fontes, a atuação dos mediadores culturais e também os veículos de publicação (KALIFA et al., 2011). As revistas, assim como os jornais, posicionam-se política e esteticamente, e participam ativamente dos processos de afirmação e defesa das novas formas de expressão literária e artística, novos gêneros, novas temáticas, experimentações estilísticas, ou de defesa contra o romantismo, então chamado de Nova Escola, de uma tradição ainda tributária da retórica e das poéticas antigas e neoclássicas.

Para Vaillant, a polêmica é inseparável das formas midiáticas, "consubstancial à prática jornalística", pois, para além da tarefa de informar, à imprensa cabe comentar e a polêmica confere uma nova dimensão ao mero comentário (KALIFA et al., 2011, p. 969). Além disso, a polêmica na imprensa traz, para o espaço impresso, uma sociabilidade da conversa em que vozes conflitantes que talvez não frequentem os mesmos ambientes sociais podem dialogar em confronto.

O poeta e escritor Alphonse Esquiros, em artigo publicado no número de novembro do periódico La France littéraire, critica o texto de Fauriel, afirmando outro método de leitura de uma obra literária, aquele que estabelece relações entre a obra de um poeta e a sociedade de 
seu tempo. La France littéraire, de Charles Malo, é o periódico que já publicara, no mesmo ano, em abril de 1834, a série de artigos de autoria de Théophile Gautier intitulada "Exumações literárias"6 contra a qual o jornal Le Constitutionnel lançara uma campanha de ataques na imprensa que os levarão aos tribunais?

Em "Exumações literárias", Gautier constrói uma galeria de retratos literários de poetas do século XVI, que o neoclassicismo francês havia relegado ao esquecimento em seu movimento de recusa dos excessos do barroco, "sacudindo as hierarquias habituais da história acadêmica" (KALIFA et al., 2011, p. 1173). La France littéraire compõe, com outros periódicos, uma "pequena imprensa literária" - como Le Cabinet de lecture, Le Mercure au XIXe siècle, L'Amulette, Le Journal des gens du Monde - amiga dos "pequenos românticos", grupo de escritores e artistas de que fazem parte os românticos frenéticos, entusiastas da obra de Victor Hugo, rival direto de Guizot, ministro da Instrução Pública, protetor de Fauriel.

Ressaltamos alguns aspectos do artigo de Esquiros que ilustram posicionamentos antagônicos. Ele começa sua crítica ao trabalho de Fauriel, afirmando serem Shakespeare e Dante dois gênios "que formam naquele momento toda a poética da Nova escola" (ESQUIROS, 1834, p. 31). E uma nota assinada pelo diretor da revista indica que o objetivo do artigo é preencher a lacuna deixada por Fauriel e "explicar a obra pelo homem, o homem por seu século" (ESQUIROS, 1834, p. 31). Para Esquiros, ambos, Shakespeare e Dante, surgem em um momento de transição - no que se refere a Dante, no momento de uma "fusão completa e definitiva do mundo pagão na sociedade católica" (ESQUIROS, 1834, p. 31) - e, desse modo, para compreender Dante, seria preciso vê-lo como "um signo misteriosamente algébrico com o qual a Providência resumiu, conteve e formulou o século XIII" (ESQUIROS, 1834, p. 31).

O articulista estabelece uma relação entre o tema da Divina comédia e um mistério dramático representado em Florença, em três atos que representavam, respectivamente, o inferno, o purgatório e o paraíso, mistério a que Dante não teria assistido, mas que marcara seu ambiente (ESQUIROS, 1834, p. 36).

A respeito do conflito que opôs guelfos e gibelinos, Esquiros projetou Dante em sua própria atualidade política ao afirmar que foi ali que começou "a grande luta entre o poder e a liberdade, que, quatro séculos depois, vai convulsionar toda a superfície da Europa", e acrescenta: "Situado [...] entre a democracia que se rebela e a feudalidade que se defende, Dante assume um partido e se declara pelos povos" (ESQUIROS, 1834, p. 37). Dante teria então lutado pela libertação intelectual dos homens, o que teria levado à Revolução Francesa. Esquiros (1834, p. 37-38)

6 Que serão mais tarde, publicados em formato de livro com o título Les Grotesques (Os grotescos, 1844).

$7 \mathrm{O}$ que teria levado Gautier a escrever o prefácio de Mademoiselle de Maupin (1835), um dos textos fundadores da estética da Arte pela Arte. 
declara, enfaticamente que "todas as coisas humanas têm duas pontas; esta [a Revolução francesa] se estende entre Dante e Napoleão; o primeiro abrindo a cratera da revolução e o outro fechando-a; o começo e o fim", pois Dante "pertence a toda a humanidade", não está circunscrito a Florença ou aos séculos XIII e XIV. Por outro lado, é um gênio que só pode ser compreendido em seu século, sobre o qual exerce duas ações, um impacto político e um impacto literário (ESQUIROS, 1834, p. 41). O exilado que nada tinha era um rei: "Quem era mais Papa na Itália do século XIV, Urbano VIII ou Dante?” (ESQUIROS, 1834, p. 41). Pergunta retórica, o próprio Esquiros responde que a cabeça que reina não é aquela que suporta a coroa, mas aquela que contém uma ideia. Além disso, nós nada saberíamos a respeito dos governantes de Florença sem a honra que lhes fez o ódio de Dante. E o povo que tem a inteligência de identificar o gênio, ao vê-lo passar, dizia: "Esse homem vem do Inferno" (ESQUIROS, 1834, p. 42).

Sua presença, por si só, já seria um libelo contra a tirania. Dante é o profeta dos tempos modernos, os argumentos voltados para a singularidade e a excelência de Dante se enfileiram, comprovando que o literato é superior ao político, o que seria ainda atual no contexto do romantismo. A biografia de Dante seria um libelo de defesa da excelência do poeta Victor Hugo diante da mediocridade do político Guizot, protetor de Fauriel? Seria uma leitura coerente com um imaginário caro aos românticos do artista como o novo aristocrata.

No que se refere a seu impacto sobre a poesia e a arte, Esquiros (1834, p. 47) enfatiza que Dante foi o primeiro autor a ter um estilo, sua obra traz a marca de uma individualidade intelectual, cuja natureza de poeta passa integralmente para o verso. Segue-se uma longa descrição dos processos de criação poética, que expõe uma visão quase religiosa da poesia, a qual faz do poeta um Criador, após o que Esquiros volta-se para a escolha linguística de Dante, que valorizou suas raízes populares: "é no idioma popular que os grandes homens foram buscar o elemento de suas obras primas" (ESQUIROS, 1834, p. 50). E o dialeto italiano da Toscana torna-se a língua italiana: "O idioma se tornou língua ao atravessar o poeta" (ESQUIROS, 1834, p. 50).

$\mathrm{O}$ articulista realiza, então, uma análise do estilo imagético de Dante, e o que ele afirma a respeito do poeta toscano poderia perfeitamente ser aplicado ao poeta Victor Hugo. A conclusão de sua leitura apresenta-se inevitável: "Dante mereceria ser chamado o primeiro grande poeta romântico" (ESQUIROS, 1834, p. 53).

A crítica que Esquiros e La France littéraire fazem ao ensaio de autoria de Fauriel foi, por sua vez, refutada, no número seguinte, por Pierre-René Auguis (1835, p. 5), membro da Société des Antiquaires, com o provocante título "Um capítulo da história dos preconceitos literários, 
Dante", apresentado pelo diretor da revista como uma prova de sua imparcialidade. Tal polêmica é objeto de estudos realizado por André Pézard (1963) e Pittwood (1985).

Para além dos posicionamentos conflitantes em uma perspectiva da constituição da autonomia do campo literário, podemos ver o choque de grupos e veículos de publicação rivais, assim como ler um capítulo das narrativas de construção de identidades nacionais, em confronto com outras culturas. Os românticos, sejam eles historiadores, literatos, pintores, arquitetos ou músicos, têm uma forte consciência do passado. Interessaram-se, sobretudo, pelos tempos medievais e renascentistas que, em sua visão, teriam construído as fundações dos tempos modernos e aberto os caminhos que seriam por eles trilhados. A aguda consciência de uma temporalidade que encerra grandes transformações vem acompanhada de um olhar otimista quanto às possibilidades de progresso que são trazidas pelas violentas mudanças provocadas pelas revoluções. É esse modo de apropriação de um passado que repercute no presente que os faz erguer para vultos como Dante estátuas, para celebrá-los como seus precursores.

\section{Referências}

AROUX, E. Dante hérétique, révolutionnaire et socialiste révélations d'un catholique sur le Moyen Age. Paris: Jules Renouard, 1854.

AUGUIS, P.-R. Un chapitre de l'histoire des préjugés littéraires: Dante. In La France Littéraire, Paris, 17:5-48, 1835.

BOURDIEU, P. Les règles de l'art. Genèse et structure du champ littéraire. Paris: Seuil, 1992.

COUNSON, A. Dante en France. Paris: Fontemoing: Erlangen-Junge, 1906.

DELACROIX, E. Journal 1822-1863. Paris: Plon, 1996.

. Notice explicative Bibliothèque. In GISORS, A. de. Le Palais du Luxembourg fondé par Marie de Médicis Régente considérablement agrandi sous le règne de Louis-Philippe I Ir. Paris: Typographie de Plon Frères, 1847.

DOTTOLI, G. et al. Les traductions de l'italien en Français au XIXe siecle. Fasano; Paris: Schena; Presse de l'Université de Paris, 2004.

ESPAGNE, M. Claude Fauriel en quête d'une méthode, ou l'Idéologie à l'écoute de l'Allemagne. In Romantisme, Paris, 21(73): 7-18, 1991.

. La notion de transfert culturel. In Revue Sciences/Lettres, Paris, 1, 2013. http://bit.ly/2hiqwD2 Acesso: 07/09/2015. 
ESQUIROS, A. Dante. In La France littéraire, Paris, 16:31-72, 1834.

FAIDER, P. Albert Counson. In Revue Belge de Philologie et D'histoire, Paris, 12(4):1484-1488, 1933.

FAURIEL, C.-C. Dante. In Revue des Deux Mondes, Paris, 3:37-92, out. 1834.

. Dante e le origini della lingua e della letteratura italiana. Per Fauriel. Palermo: La Società Libraria, 1856.

. Dante et les origines de la langue et la littérature italiennes. Cours fait à la Faculté de Lettres par M. Fauriel. Vol. 2. Paris: Auguste Durand, 1854.

GAUTIER, T. Salon de 1840. In La Presse, 13 mar. 1840. http://bit.ly/2h9w2K8 Acesso: 20/09/2015.

HUGO, V. Préface de Cromwell. Paris: Larousse, 1972.

JULLIAN, P. Delacroix. Paris: Albin Michel, 1963.

KALIFA, D. et al. La civilisation du journal. Histoire culturelle et littéraire de la presse française au XIXe siècle. Paris: Nouveau Monde, 2011.

LOICQ-BERGER, M.-P. Survie d'un lion: Alcibiade - $2^{\text {ème }}$ partie: le dossier iconographique. In Folia Electronica Classica, Louvain, (10), 2005. http://bit.ly/2hf7SLY Acesso: 17/09/2015.

MAINGUENEAU, D. Discours littéraire. Paris: Armand Colin, 2004.

PÉZARD, A. Comment Dante conquit la France aux beaux jours du Romantisme (1830-1855). In PELLEGRINI, C. (org.). Studi in onore di C. Pellegrini. Torino: Società Editrice Internazionale, 1963, p. 683-706.

PITTWOOD, M. Dante and the French romantics. Genève: Droz, 1985.

VEGLIANTE, J.-C. Perception française de l'Italie et traduction de l'italien: histoire d'un malentendu. In Romantisme, Paris, 29(106): 61-81, 1999. http://bit.ly/2gw4jTa Acesso: 31/07/2016.

WALLACE collection guide. London: The Trustees of the Wallace Collection, 1997.

Recebido em 30/03/2016

Aprovado em 15/05/2016 